\title{
Evolutionary Approach to Concentration of Production Efficiency Assurance at the Sectoral Level
}

Gallyamova D.Kh.

Kazan Federal University, Institute of Management, Economics and Finance, Kazan, 420008, Russia

Malganova I.G.

Kazan Federal University, Institute of Management, Economics and Finance, Kazan, 420008, Russia

Bagautdinova N.G.

Kazan Federal University, Institute of Language, 420008, Kazan, Russia

Grigoryeva L.L.

Kazan Federal University, Institute of Management, Economics and Finance, Kazan, 420008, Russia

Doi:10.5901/mjss.2014.v5n28p14

\section{Abstract}

This article is devoted to analysis of production concentration processes at modern stage which indicates evolutional origin of this phenomenon, which requires the use of different approaches to managing and evaluation of their efficiency at all economic levels. It deals with characteristic features of production concentration management at the branch level taking into account existing approaches to the branch development; managing changes in the interaction of individual sectors' agents caused by globalization processes in the economy; methods to solve problems of production concentration management, in particular, to form a network configuration and evaluate its efficiency.

Keywords: business concentration, business centralization, evolutionary approach, internalization, organizational structure.

\section{Introduction}

The most typical forms of production concentration at the branch level are mergers and acquisitions. New quality of the branch development can be revealed by analysis of these processes proceeding specificity. To study dynamic development of mergers and acquisitions, it is necessary to note that they have been undulating during all their history. Five most strongly marked waves in the development of these processes can be distinguished:

- $\quad$ wave of mergers in 1887-1904;

- mergers of companies in 1916-1929;

- wave of conglomeration mergers in the 60-70-s of the XXth century;

- $\quad$ wave of mergers in the 80-s;

- $\quad$ mergers in the late $90-\mathrm{s}$. [1]

Preconditions for this or another merger waves are global and suppose entering a new level, therefore, in order to manage branch structural shifts with the help of production concentration on the basis of stable development conception, it is necessary to use technologies of evolutional changes management. Development of such technologies supposes analysis and generalization of theoretical models and concepts.

The birth of modern evolutional theory of macroeconomic growth goes back to the seventies of the XXth century. By this time it was possible to talk about logical completion R.Solow's model by D.Cass. Nevertheless, the technical and scientific progress remained undeclared within this model. This supposed the necessity of additional studies and research on R.Nelson and S.Winter's evolutional economics which was conducted simultaneously with this model's development. They considered the main attention in growth to belong to innovations, competition as a process of natural selection and problems of accidents and uncertainty. 


\section{Method}

The basis of academic approach being analysed is examination of alternative classical postulates of rationalization principles of corporations, companies and other agents of economic development behavior. In a number of forms of the market agents' rationality distinguished by O.Williamson such forms are marked: rationality maximization (neoclassical economic theory), limited rationality (economic theory of transactional costs) and organic rationality (evolutionary school). [4]

\section{Result}

Analysis of these changes allows to make a conclusion that in theoretical evidence rationality of economic entity successively decreases and its organicity according to living organisms' behavior example increases. Enhancement of organicity and decrease in rational behaviour level are typical for today's branch markets with connection to which it is logical to apply this management process to the process of their management which is based on minimal rationality of economic agents.

Low level of rationality is used in modern evolutionary approach and approach of Austrian school. Both types of economic thought are distinguished by the chosen level of the the object of research. Thus, Nelson and Winter analyse evolutionary development both inside and between enterprises. The first type is microlevel, the second - meso level (branch level) which allows to use this approach for research and management of the branch development. Austrian school considers processes of more general level connected to the institutes of money, markets, aspects of ownership and right as itself. At the same time the later, according to representatives of the given approach, can not be planned. Although possibility of economy on transactional costs is definitely closely connected to the problem of the institute's viability, which is a subject of studies in Austrian school and, therefore, union of these approaches could be useful. [2] Research problems on rational organicity theory and transactional costs of economic theory in present time are versatile. Nonetheless, they supplement each other, therefore, we shall also consider the second movement's approach to evolutional theory in the given research.

For conceptual management technologies development by production concentration at the approach level, the method of evolutional changes is interesting and useful which can act as the basis of production centralization technology. [5] In connection to this fact, it is important to mention that functioning of each social and economic system is characterized by existence of five processes:

1) metabolism, i.e. exchange with the environment or, in a narrower sense, transformation of incoming flows into outcoming. At the branch level this signifies transformation of raw feedstock into finished product necessary for other branches and enterprises;

2) reproduction, i.e., re-creation of basic reproduced conditions and functioning, preservation and improvement of system condition. In terms of economic development this means following the principles of stable development conception;

3) evolution, i.e., changes in this system's characteristics on the basis of self-organization mechanisms, moving motive of which for industrial branches are the maintenance and enhancement of competitiveness;

4) harmonization of inner system space, i.e., provision of inner unity, agreed functioning and development of inner undersystems and also agreement with the external environment. For the industrial branch it is necessary to talk about progressive structural shifts, the content of which was analysed above;

5) replication, i.e., birth of self-similar systems. An example of such a display of the evolutionary approach is the distribution of successful models of individual enterprises behaviour through centralization of production. [10]

The use of ways and methods of evolutional theory in the process of production concentration indentification as technology of progressive structural shifts financing at the branch level supposes identification of the given process phases with division on micro-, meso- and macrolevels of research and also exposure of reasons (moving forces) and stimuli (managing influences), determining the phase change.

Specificity of the branch development and place of national branches in hierarchy of global economics is determined, if other conditions are equal by the most widespread models of separate corporations behavior, total effectiveness of which is formed by the level of branch competitiveness as a mesosystem. [6] The given fact indicates microlevel importance of bases and preconditions of production centralization. Here we can distinctly observe the above mentioned interconnection between production concentration at the level of corporate structures and production concentration at the branch level. Within the study of this phenomenon it is expedient to mention stages (models) of routines mutation (R.Nelson and S.Winter's approach)[3], and phase development of corporations' organizational 
structures (classification by A. Chandler).

From organizational point of view, any company experiences rather definite phases of its development. Transition from one phase to another can be qualified as «crisis». At the same time the period of crisis is overcome as a result of the corresponding managing decisions making.

Interest within this theory also belongs to distinguished by Nelson and Winter models of economic growth which are useful for the choice of technologies and concentration spheres at the branch level:

1) transformation of managing and technological operations:

2) transformation of traditional investment operations;

3) research activity.

The first two types of models are raised by previous experience or external environment, and «innovative activity: represents «search». The company can provide it constantly or when other models stop bringing profit. It is necessary to note that possibility of success of search activity is indirectly proportional to its scale and at the same time economic effect of search activity increases as the search scale increases.

Concentration of production has organizational basis determining the type of investment flows management. The rise of the companies' systematic features in the process of organizational adaptation within evolutional theory of management was investigated in detail and presented by A.Chandler. [7] Thus, in the early XXth century the full cycle of the companies' organizational adaptation took from 10 to 20 years. However, in our time pace of the environment changes has significantly increased that supposes constant change of external factors influencing the company, as a result, its time supply is significantly lower. [11] To react quickly to the environment changes and manage the company effectively in the changing conditions, companies use the accumulated experience of organizational changes that allows to reduce the process of organizational adaptation down to several years and even a year.

And the type of business and company's organizational structures interrelation supposes evolutional change by stages:

1) simple organizational structure;

2) combination of capitals united mainly by property and financial links;

3) functional organizational structure;

4) multidivisional organizational structure. [9]

Change into phase of organizational management is caused by characteristic features of scientific and technical progress requiring consolidation of economic resources for provision of advantages of branch scale effect. As a result, serious evolution of branch companies' demography occurs in direction of economically strong corporations consolidation. Motivation to use this model is determined by a number of preconditions marked by us in the system of factors of multilevel management of production centralization. Strategy of vertical integration for the entire technological chain becomes dominant. Thus, with increase of the sizes such organizations encounter certain difficulties: they gradually lose ability to distribute resources effectively, reduce production costs and make successful investments. Moreover, difficulties during diversification of business occur, since the number of management level increases, flows of information between different bank spheres become more complicated. Increased need for enhancement of efficiency to meet the consumer's demands is observed.

Uneffectiveness of functional organizational structure during production of diversified goods, use of alternative technologies and sale in various markets caused creation of the fourth phase of organizational form. [12] At this stage radical companies' reorganization is held and multidivisional organizational structure is inculcated. Its use during realization of centralization allows to combine centralization of management with operational divisions' independence in making current production decisions which stimulates internal corporative competitiveness.

Integrating A.Chandler's approach with an idea of enterprises' chain as a modern stage of organizational development requiring specific technologies of business concentration different from the generally accepted, it is expedient to offer the broadened typology of organizational structures. [8] Since we observed the importance of the static as well as dynamic characterisitcs of development within evolutional approach, it is possible to agree with the necessity to describe their changes in time with the help of introduction of the network structure notion in which connections between all members potentially exist.

\section{Conclusion}

Thus, duality of the companies' statics and dynamics consideration allows to solve a number of tasks in production concentration management including the formation of the network configuration and estimate its effectiveness. Evolutionary theory allows to differentiate needs in alternative technologies of business concentration since in the 
changing indefinite environment in which branch market is presented, characterized by technological changes and market openness, network contacts as a way of continual enhancement of competitiveness is a more preferrable form of the branch development. Evolutionary study of the companies' organizational structures allows to distinguish several phases, change to which is carried out under external environment pressure and, therefore, under pressure of global changes in economic systems. With change from one phase to another level of corporation structures concentration increases which leads to transformation of their interrelation within a branch.

Thus, it is possible to conclude that production concentration at the level of corporate structures caused by globalization processes in economics leads to organizational changes in the subjects' interrelation of separate branches.

\section{References}

M. Afanasyev, AL Myasnikov global competition and clustering economy // Problems of Economics. 2005. №4. S. 75-86.

Galliamova DH Features of the process of centralization of production in a globalizing world economy. Development background, problems and perspektivy.-K. Univ Kazansk.un Press, 2007. 228 pp.

Nelson, RR, Winter SJ. Evolutionary Theory of Economic izmeneniy.- M .: Case, 2002.- 536 p.

O. Williamson Behavioral background of modern economic analysis // Oliver E. Williamson. Behavioral Assumptions. In: O.E. Williamson. The Economic Institutions of Capitalism. Firms, Markets, Relational Contracting. N.Y .: The Free Press, 1985, p.44 52.

F. Scherer, Ross D. The structure of industrial markets: Per. with Eng. / M.: Infra-M, 1997.-698

Cavusgil S.T. Differences among exporting finns based on degree of inemationalization. Journal of Business Research, 1984, 12.

Chandler A.D. Jr. Str and structure: Chapters in the history of the American industrial enterprise. - Cambridge, Mass, and London: MIT Press. 1962.

Kleiner GB Features of the formation and evolution of the socio-economic institutions in Russia // Preprint., 2001. 126 p.

North D. Institutional Economics. Institutions, Institutional Change and Economic Research Center /I Source "SocioEgo" http://www.socioego.ru

Polterovich V., Popov Evolutionary Theory of Economic politiki.Ch.1 // Problems of Economics. 2006.№7. S.4-23, №8. S.46-65.

J. Schumpeter, Capitalism, Socialism and Democracy. M., 1995.Alchlan A. Uncertainty, Evaluation and Economic Theory // Journal of Political Economy, June 1950, p.211-221.

Razumovskaya, E.M. , Kutsevol, N., Popov, M., Mishakin, T., Leto, L., Tsalikova, V. The effectiveness of management practice in the market of socially important services. Asian Social Science, Volume 10, 28 September 2014, Pages 118-122

Razumovskaya, E.M.,Lapidus, L.V., Mishakin, T.S., Popov, M.L. Features and peculiarities of the Russian passenger rail market development. Mediterranean Journal of Social Sciences vol. 5 (18 SPEC. ISSUE), pp. 165-170.

Safiullin Lenar, Fatkhiev Artur, Saipullaev Ullubi, Bagautdinova Nailya. Problems and decision in the field of distance education. Procedia - Social and Behavioral Sciences. Vol. 131, pp. 111-117 // 3rd World conference on educational technology researches Turkey 07-09.11.2013. 